CLINICAL STUDY

\title{
Serum CXCL10 levels and occurrence of thyroid dysfunction in patients treated with interferon- $\alpha$ therapy for hepatitis $\mathrm{C}$ virus-related hepatitis
}

\author{
Mario Rotondi, Roberta Minelli ${ }^{1}$, Flavia Magri, Paola Leporati, Paola Romagnani ${ }^{2}$, Maria Cristina Baroni ${ }^{1}$, \\ Roberto Delsignore ${ }^{1}$, Mario Serio ${ }^{2}$ and Luca Chiovato \\ Unit of Internal Medicine and Endocrinology Fondazione Salvatore Maugeri IRCCS and Chair of Endocrinology, University of Pavia, Pavia, Italy, ${ }^{1}$ Unit of \\ Endocrinology, University of Parma, Parma, Italy and ${ }^{2}$ Excellence Center for Research, Transfer and High Education DENOthe, University of Florence, \\ Florence, Italy \\ (Correspondence should be addressed to L Chiovato; Email: lchiovato@fsm.it)
}

\begin{abstract}
Objective: Thyroid autoimmunity is a common side effect of interferon- $\alpha$ (IFN- $\alpha$ ) treatment for chronic hepatitis $C$. There are currently no reliable parameters to predict the occurrence of thyroid dysfunctions in patients undergoing IFN- $\alpha$ therapy. CXC chemokine ligand 10 (CXCL10) is a chemokine known to play a role in both thyroid autoimmune disease and hepatitis $\mathrm{C}$ virus (HCV) hepatitis.

Design: The aim of this study was to evaluate serum CXCL10 levels in HCV patients treated with IFN- $\alpha$ in relation to the occurrence of thyroid dysfunctions. Serum CXCL10 levels were assayed in $25 \mathrm{HCV}$ patients (proven to be negative for serum thyroid antibodies) before and during IFN- $\alpha$ therapy (2, 4 and 6 months) and in 50 healthy controls. HCV patients were retrospectively selected according to the occurrence of IFN- $\alpha$-induced thyroid dysfunction and were assigned to two groups. Group I included 15 patients who did not develop thyroid antibody positivity or dysfunction; group II included ten patients who showed the appearance of serum thyroid antibodies, followed by clinically overt thyroid dysfunction.

Results: Patients with HCV, regardless of the development of thyroid dysfunctions, had significantly higher serum CXCL10 than controls $(261.6 \pm 123.4$ vs $80.4 \pm 33.6 \mathrm{pg} / \mathrm{ml} ; P<0.00001)$. Pretreatment mean serum CXCL10 levels were significantly higher in Group I versus Group II (308.6 \pm 130.7 vs $191.1 \pm 69.4 \mathrm{pg} / \mathrm{ml} ; P<0.05)$. Groups I and II showed different rates of favourable response to IFN- $\alpha$ treatment (33 and $90 \%$ respectively).

Conclusion: Our results suggest that measuring serum CXCL10 before IFN- $\alpha$ treatment may be helpful for identifying those patients with higher risk to develop thyroid dysfunction, and require a careful thyroid surveillance throughout the treatment.
\end{abstract}

European Journal of Endocrinology 156 409-414

\section{Introduction}

Interferon- $\alpha$ (IFN- $\alpha)$ has become the standard therapy for chronic hepatitis $\mathrm{C}$, inducing a biochemical (persistent normalisation of serum alanine-aminotransferase) and virological (sustained negative results for hepatitis $\mathrm{C}$ virus (HCV) RNA) response in about $15-25 \%$ of treated patients (1). It has been suggested that HCV might share partial sequences in a few amino acid segments with thyroid tissue antigens (2) and that virus-related factors, mainly HCV infection itself, might predispose to the development of thyroid autoimmune disease (3-5). In accordance with this hypothesis, some viral features (infection with mixed HCV genotypes and lower HCV RNA levels) have been reported to be associated with an increased risk for developing thyroid disease (6). Thyroid autoimmunity has been widely reported, also as a side effect of interferon-treatment, with a frequency ranging from 2.5 to $45.3 \%$ (7-10), but its pathophysiological mechanisms remain still unclear.

Chemokines are a recently identified family of cytokines that induce the chemotaxis of different leukocyte subtypes (11). The major function of chemokines is the recruitment of leukocytes to inflammation sites, but they also play a role in tumoural growth, angiogenesis and organ sclerosis $(12,13)$. At present, more than 50 chemokines have been described, which have been classified into four major families $(11,14)$. Among chemokines of the CXC family, CXC chemokine ligand 10 (CXCL10) plays an important role in several human autoimmune and non-autoimmune diseases, 
including chronic autoimmune Hashimoto's thyroiditis (HT), Graves' disease (GD) and HCV-related hepatitis (14-18). HCV infection induces an acute and chronic liver inflammation through an immune-mediated pathway that may lead to cirrhosis and liver failure (19). HCV-related hepatitis is characterised by a dramatic lymphocyte infiltration into the liver, mainly comprised of HCV non-specific cells. Several data indicated that IFN- $\gamma$ secretion by intrahepatic lymphocytes may drive non-specific cell homing to the liver. This effect is mediated by CXCL10 production. Several clinical studies evaluated the changes of serum CXCL10 in patients with HCV hepatitis undergoing IFN- $\alpha$ therapy $(18,20)$, showing that a successful virological response to IFN- $\alpha$ therapy is characterised by a marked decrease in the intrahepatic, as well as in the serum, levels of CXCL10. Investigations concerning a possible relation between serum chemokines and treatment outcome in patients with HCV-hepatitis demonstrated that lower pretreatment levels of CXCL10 are significantly associated with a favourable therapeutic response to IFN- $\alpha$. This finding indicated a role of CXCL10 measurement in patients with HCVhepatitis for predicting a favourable response to the treatment with IFN- $\alpha$ (21).

The issue of INF- $\alpha$-related thyroid dysfunction has been widely investigated in patients with HCV hepatitis (22). Despite previous studies reporting that the risk for developing thyroid dysfunction during IFN- $\alpha$ therapy is closely correlated with mixed HCV genotype infection and lower HCV RNA levels, female gender, pretreatment positivity for thyroid antibodies (particularly TPO Ab) and a hypoechoic pattern of the thyroid gland at ultrasound, none of the above features has enough specificity and sensitivity to reliably predict the occurrence of thyroid dysfunction (22).

The aim of the present study was to evaluate pretreatment and on-treatment serum levels of CXCL10 in patients undergoing IFN- $\alpha$ treatment for HCV hepatitis, in relation to the development of thyroid autoimmune dysfunctions. IFN-related thyroid autoimmune diseases (IFN-AT) are commonly thought to reproduce the natural history of HT both in its shortand long-term outcome (23). As a consequence, IFN-AT has been proposed as an experimental model for human thyroid autoimmunity (24). For this reason, the evaluation of serum CXCL10 in HCV patients developing thyroid dysfunction may allow evaluating the chemokine changes from the onset of the autoimmune process throughout its variable clinical course, and hopefully provide further knowledge on CXCL10 behaviour in chronic autoimmune thyroiditis.

\section{Patients and methods}

The study group encompassed 25 patients ( 18 male and 7 female) with HCV-related chronic hepatitis and 50 sex- and age-matched healthy controls. All patients took a course of IFN- $\alpha-2$ a at doses ranging from 3 to 6 MU three times a week for at least 6 months. Patients were retrospectively selected from a larger population of HCV patients treated with recombinant IFN- $\alpha$ at the Department of Internal Medicine and Endocrinology of the University of Parma between 1992 and 1995. Selection criteria for patients were as follows: i) availability of frozen serum samples stored at $-20{ }^{\circ} \mathrm{C}$; ii) negative pre-IFN- $\alpha$ tests for thyroid antibodies; iii) availability of serum thyroid FT4, FT3, TSH, Tg Ab and TPO Ab levels before IFN- $\alpha$ therapy and every 2 months in the course of treatment and iv) detailed medical records, including both the outcome of HCV hepatitis and the thyroid disturbances. Patients were assigned to two groups according to the occurrence or not of thyroid autoimmune dysfunction during IFN- $\alpha$ treatment. In detail, Group I included 15 patients who neither develop thyroid dysfunction nor converted to thyroid antibody positivity throughout the study span. Group II included ten patients in whom the treatment with IFN- $\alpha$ lead to the appearance of serum thyroid antibodies ( $\mathrm{Tg} \mathrm{Ab}$ and/or TPO Ab), followed by a clinically overt thyroid dysfunction. Mandatory inclusion criteria for patients assigned to Group II were that the thyroid dysfunction was persistent and required specific treatment. In detail, five patients (three male and two female) developed GD, while autoimmune thyroiditis was diagnosed in the remaining five patients. The diagnosis of GD was established from the clinical presentation and by thyroid hormones and thyroid autoantibodies measurements. Thyroid scintiscan was performed in all cases and was consistent with Graves' hyperthyroidism. All GD patients were given methimazole therapy, at doses ranging from 15 to $25 \mathrm{mg} /$ day (and, when necessary, $\beta$-blockers to control cardiac rate). The diagnosis of autoimmune thyroiditis was established from the clinical presentation, thyroid hormones and thyroid autoantibodies measurements and/or thyroid ultrasonography (decreased and dyshomogeneous echogenicity). All patients were hypothyroid $(\mathrm{TSH}>3.5 \mu \mathrm{U} / \mathrm{ml})$ and were given levothyroxine $\left(\mathrm{L}-\mathrm{T}_{4}\right)$ at replacement doses.

The retrospective design of the present study, together with the fact that patients were specifically selected for the development of a clinically overt thyroid dysfunction requiring active treatment, does not allow drawing conclusions on the epidemiology of INF- $\alpha$-related thyroid dysfunction and/or to success rate of IFN- $\alpha$ treatment for liver disease. Pretreatment parameters, including viral and pharmacological information for patients belonging to different groups, are shown in Table 1. Serum CXCL10 levels were assayed in all patients before IFN- $\alpha$ and at 2, 4 and 6 months after the starting therapy. The study was performed according to Helsinki protocol and was approved by the local ethical committee. 
Table 1 Pretreatment clinical characteristics of patients subdivided according to the development of thyroid dysfunction during the treatment with interferon- $\alpha$ (IFN- $\alpha$ ) for hepatitis C virus-related hepatitis.

\begin{tabular}{lccc}
\hline & Group I & Group II & P value \\
\hline $\begin{array}{c}\text { No. of } \\
\text { patients }\end{array}$ & 15 & 10 & \\
$\begin{array}{c}\text { Sex (M/F) } \\
\text { Age (years) }\end{array}$ & $40(29-63)$ & $45(25-62)$ & 0.357 \\
IFN- $\alpha$ dose & $18(9-18)$ & $15(6-18)$ & 0.422 \\
(MU/week) & & & \\
FT3 (pg/ml) & $4.0(2.7-5.6)$ & $3.3(2.9-5.4)$ & 0.978 \\
FT4 (pg/ml) & $11.0(7.3-17.0)$ & $13.5(8.0-16.8)$ & 0.311 \\
TSH (mU/l) & $1.5(0.9-2.3)$ & $1.3(1.0-1.6)$ & 0.238 \\
CXCL10 & $\mathbf{3 1 2 . 6 ( 7 8 . 6 - 4 5 6 . 5 )} \mathbf{1 7 5 . 1 ( 8 3 . 9 - 2 8 2 . 4 )}$ & $\mathbf{0 . 0 4 8}$ \\
(pg/ml) & & & \\
\hline
\end{tabular}

The parameters showing significant differences between the two groups are in bold characters.

\section{Serum CXCL10 measurements}

Serum CXCL10 levels were assayed by a quantitative sandwich immunoassay (25) using a commercially available kit (R \& D Systems, Minneapolis, MN, USA), with a mean minimum detectable dose of $1.67 \mathrm{pg} / \mathrm{ml}$ and a maximum detectable dose of $500 \mathrm{pg} / \mathrm{ml}$. The intra- and inter-assay coefficients of variation were 3 and $6.1 \%$ respectively. Samples were assayed in duplicate. Quality control pools at low, normal and high concentrations for all parameters were present in each assay respectively.

\section{Statistical analysis}

Statistical analysis was performed using SPSS software (SPSS, Inc., Evanston, IL, USA). Serum parameters were compared between groups by means of Student's $t$-test for unpaired data and Mann-Whitney $U$ test owing to normal or non-parametric distribution. Correlation between two variables was ascertained by Pearson and Spearman's correlation tests as appropriate. Frequencies of favourable therapeutic response were compared among groups by $\chi^{2}$ test and Fisher's exact correction. Successful response to the treatment was defined as persistent normalisation of serum aminotransferases. $P<0.05$ was considered statistically significant. Results are expressed in the text as mean \pm s.E.M. unless otherwise stated.

\section{Results}

Before treatment, the serum levels of CXCL10 were significantly higher in the entire cohort of patients with HCV-related hepatitis when compared with healthy subjects $(261.6 \pm 123.4$ vs $80.4 \pm 33.6 \mathrm{pg} / \mathrm{ml} ; P<$ $0.00001)$. Group I patients had significantly higher pretreatment mean serum CXCL10 levels when compared with Group II patients (308.6 \pm 130.7 vs
$191.1 \pm 69.4 \mathrm{pg} / \mathrm{ml} ; \quad P<0.05)$. A difference was consistently observed at all time points during IFN- $\alpha$ treatment, with patients in Group I showing consistently higher serum CXCL10 levels when compared with Group II patients. The changes in serum levels of CXCL10 throughout IFN- $\alpha$ therapy are shown in Fig. 1.

In the whole group of patients receiving IFN- $\alpha, 14$ out of 25 patients $(56 \%)$ had a favourable response to the treatment. When patients from Groups I and II were analysed separately, the rate of favourable responses was different, with 5 out of 15 (33\%) complete responders found in Group I as opposed to 9 out of 10 $(90 \%)$ complete responders in Group II. As shown in Fig. 2, such a difference did not reach statistical significance, which was most likely due to the limited number of patients enrolled. Similarly, the pretreatment

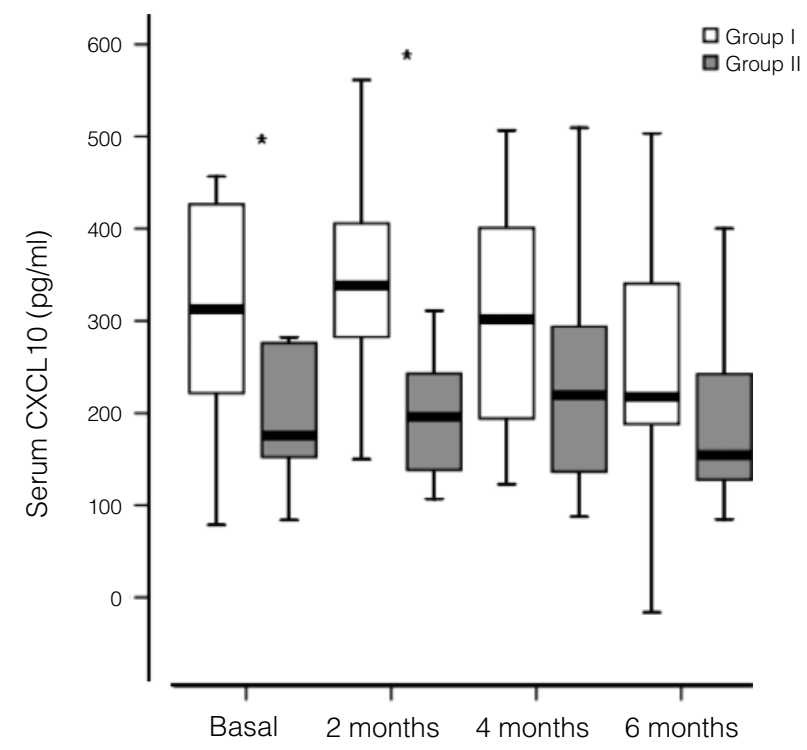

Figure 1 Pretreatment and on-treatment serum levels of CXCL10 in $\mathrm{HCV}$ patients treated with IFN- $\alpha$ in relation to the occurrence of or less thyroid dysfunction in the course of therapy. Data are expressed as median plus 25th and 75th percentiles in boxes, and 5th and 95th percentiles as whiskers. ${ }^{*}$ Indicates statistical significance (Mann-Whitney $U$ test; $P<0.05$ ).

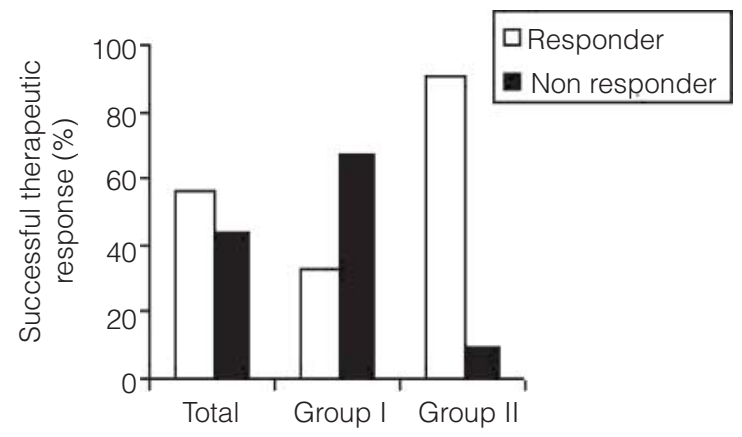

Figure 2 Frequencies of favourable response to IFN- $\alpha$ therapy in the whole cohort of HCV patients and according to the occurrence of or less thyroid dysfunction in the course of treatment. 
serum CXCL10 levels were lower in patients showing a favourable response to the treatment than patients who failed to achieve remission (305.7 \pm 140.3 vs $226.9 \pm$ $100.2 \mathrm{pg} / \mathrm{ml}$ respectively) but not in a statistically significant manner.

\section{Discussion}

The results of this study confirm that serum CXCL10 levels are significantly increased in patients with HCV chronic hepatitis, when compared with sex- and age-matched healthy volunteers. Furthermore, the development of overt thyroid dysfunction in the course of IFN- $\alpha$ therapy is associated with significantly lower serum levels of CXCL10, both before and during the treatment. This finding seems particularly relevant as it suggests that pretreatment serum levels of CXCL10, previously proven to have a predictive value for a favourable response to IFN- $\alpha$, could also be useful to identify patients more prone to develop thyroid dysfunction during IFN- $\alpha$ treatment for HCV hepatitis. The clinical importance of such a finding stems from the fact that the difference in serum CXCL10 levels between patients who did or did not develop IFN- $\alpha$-associated thyroid dysfunction was evident before starting IFN- $\alpha$ therapy. This would imply that serum CXCL10 measurement would allow identifying those patients in whom thyroid surveillance during IFN- $\alpha$ therapy should be more careful. Prompt diagnosis and early treatment of IFN- $\alpha$-associated thyroid dysfunctions will be helpful to limit the necessity of stopping IFN- $\alpha$ therapy which, especially when a benefit for the liver disease is evident, may be disadvantageous (22).

The issue of predicting thyroid dysfunction occurring in patients with HCV hepatitis during IFN- $\alpha$ treatment has been previously addressed and several virus-related, therapeutic regimen-related and patient-related parameters have been identified $(6,10,22,24)$. Among the virus-related variables, it has been demonstrated that lower serum HCV RNA levels before IFN- $\alpha$ therapy are significantly associated with a higher frequency of thyroid dysfunction in the course of treatment (6). This evidence may be regarded as indirect confirmation of our results, in that lower pretreatment serum levels of CXCL10 are likely to result from a lower intra-hepatic INF- $\gamma$ production and lymphocyte infiltration sustained by a low viral load $(18,25)$. Treatment-related variables, influencing the occurrence of thyroid dysfunction, are mainly caused by the use of different IFN preparations and the dose received. Patients with cancer treated with lymphoblastoid, IFN- $\alpha-1$, had a higher frequency of early thyroid dysfunction than those treated with recombinant IFN- $\alpha$. The presence of trace amounts of IFN- $\gamma$ in natural IFN- $\alpha$ could explain the different rates of thyroid autoimmunity (26). Because all our patients received recombinant IFN- $\alpha$ and similar doses were used, we can reasonably assume that the occurrence of thyroid dysfunction was unrelated to different therapeutic modalities. The most studied and widely reported factor predisposing to thyroid dysfunction in the course of IFN- $\alpha$ therapy is pretreatment subclinical thyroid autoimmunity, as assessed by positive tests for serum $\mathrm{Tg} \mathrm{Ab}$ and TPO $\mathrm{Ab}$ and/or an hypoechoic pattern of the thyroid at ultrasound $(10$, 22 ). In accordance with the design of the present study, negative tests for thyroid antibodies at baseline constituted a mandatory inclusion criterion, therefore the predictive efficacy of measuring serum CXCL10 and/ or TPO $\mathrm{Ab}$ before treatment cannot be compared. Nevertheless, the assessment of serum CXCL10 levels may prove useful at least for those patients showing normal serum thyroid function and undetectable thyroid antibodies at baseline.

In our series, patients developing thyroid dysfunction were also more likely to display a favourable response to IFN- $\alpha$ treatment, showing nearly a three times higher rate of success. This last aspect deserves a comment. Indeed, as shown in a recent article, lower pretreatment CXCL10 levels in patients with HCV hepatitis are related to a more favourable response to IFN- $\alpha$. Furthermore, Gogas et al. (27) have recently reported that the appearance of autoantibodies or clinical manifestations of autoimmunity, during the treatment with interferon$\alpha$, is associated with a statistically significant improvement in the relapse-free survival and in the overall survival of the patients with melanoma (27). Taken together, the results of these studies would be in line with our findings indicating that patients with lower pretreatment serum CXCL10 levels develop autoimmune thyroid dysfunction more frequently and also show a higher rate of successful therapeutic response. The above findings would suggest that the measurements of CXCL10 in the serum of HCV patients before IFN- $\alpha$ therapy might predict both the development of an autoimmune thyroid dysfunction and an amelioration of the liver disease.

An additional aim of the present study was to evaluate the serum changes in CXCL10 from the onset of the thyroid autoimmune process throughout its clinical course, in order to better define the natural history of circulating chemokines in AITD. IFN- $\alpha$ induced thyroid dysfunction was thought to represent a good experimental model in that, at variance with naturally occurring thyroiditis, a precise estimation of the timing of thyroiditis development would be possible. Unfortunately, the extremely high serum levels of CXCL10 in HCV patients did not allow drawing conclusions in this regard. A more reliable model to investigate this aspect could be to evaluate CXCL10 in autoimmune thyroiditis occurring after IFN- $\beta$ therapy in patients with multiple sclerosis (28). Indeed, the latter patients show pretreatment serum CXCL10 levels similar to healthy subjects (29).

A limitation of the present study is that patients developing thyroid autoimmunity with preserved 
thyroid function were not taken into account. Indeed, it is reasonable to hypothesise that the changes in serum CXCL10 might be more evident in patients developing overt thyroid dysfunction, who also show a microenvironment more enriched in $\mathrm{T}$ helper type 1 (Th1) molecules (17). Nevertheless, given the aim of the study, which was to identify patients who require a particularly strict thyroid function surveillance during IFN- $\alpha$ therapy, it was decided to include only those patients developing overt thyroid dysfunction.

It has been recently reported that $\mathrm{HCV}$ patients developing thyroid dysfunction during IFN- $\alpha$ treatment displayed circulating markers of a Th1 immune reaction, as assessed by IFN- $\gamma$ expression by peripheral blood lymphocytes (30). Therefore, the results of our study, indicating no significant change of a Th1-related chemokine in a correspondent group of patients, would, at least partially, disagree with this previous observation (30). A possible explanation for such a discrepancy, besides the different experimental procedures, could be that, at variance with the study of Mazziotti et al. (30), our patients did not receive ribavirin, which is known to be a potent Th1 inducer.

In conclusion, our retrospective study suggests that measuring serum CXCL10 before IFN- $\alpha$ treatment may be a helpful tool for identifying the patients who will develop overt thyroid dysfunction, and therefore will require a careful thyroid surveillance throughout the treatment. Future longitudinal prospective studies enrolling large numbers of patients will be required to confirm these data.

\section{Acknowledgements}

The experiments reported in this paper were supported in part by funds from the TRESOR Research Project of the Tuscany Region (Italy) and by Progetto di Ricerca Finalizzata ex art.12, del D Lgs.502/92 - 2005.

\section{References}

1 Shiratori Y, Yokosuka O, Nakata R, Ihori M, Hirota K, Katamoto T, Unuma T, Okano K, Ikeda Y, Hirano M, Kawase T, Takano S, Matsumoto K, Ohashi Y \& Omata M. Prospective study of interferon therapy for compensated cirrhotic patients with chronic hepatitis C by monitoring serum hepatitis C RNA. Hepatology 1999 29 1573-1580.

2 Tran A, Quaranta JF, Benzaken S, Thiers V, Chau HT, Hastier P, Regnier D, Dreyfus G, Pradier C \& Sadoul JL. High prevalence of thyroid autoantibodies in a prospective series of patients with chronic hepatitis C before interferon therapy. Hepatology 199318 253-257.

3 Preziati D, La Rosa L, Covini G, Marcelli R, Rescalli S, Persani L, Del Ninno E, Meroni PL, Colombo M \& Beck-Peccoz P. Autoimmunity and thyroid function in patients with chronic active hepatitis treated with recombinant interferon- $\alpha-2 \mathrm{a}$. European Journal of Endocrinology 1995132 587-593.

4 Fernadez-Soto L, Gonzalez A, Escobar-Jimenez F, Vazquez R, Ocete E, Olea N \& Salmeron J. Increased risk of autoimmune thyroid disease in hepatitis $\mathrm{C}$ vs hepatitis $\mathrm{B}$ before, during and after discontinuing interferon therapy. Archives of Internal Medicine $19981581445-1448$

5 Antonelli A, Ferri C, Fallahi P, Ferrari SM, Ghinoi A, Rotondi M \& Ferrannini E. Thyroid disorders in hepatitis $\mathrm{C}$ virus chronic infection. Thyroid 200616 563-572.

6 Hsieh MC, Yu ML, Chuang WL, Shin SJ, Dai CY, Chen SC, Lin ZY, Hsieh MY, Liu JF, Wang LY \& Chang WY. Virologic factors related to interferon- $\alpha$-induced thyroid dysfunction in patients with chronic hepatitis C. European Journal of Endocrinology 2000 142 431-437.

7 Lisker-Melman M, Di Bisceglie AM, Usala SJ, Weintraub B, Murray LM \& Weissel M. Development of thyroid disease during therapy of chronic viral hepatitis with interferon- $\alpha$. Gastroenterology 1992102 2155-2160.

8 Carella C, Amato G, Biondi B, Rotondi M, Morisco F, Tuccillo C, Chiuchiolo N, Signoriello G, Caporaso N \& Lombardi G. Longitudinal study of antibodies against thyroid in patients undergoing interferon- $\alpha$ therapy for HCV chronic hepatitis. Hormone Research 199544 110-114.

9 Marazuela M, Garcia-Buey L, Gonzalez-Fernandez B, GarciaMonzon C, Arranz A, Borque MJ \& Moreno-Otero R. Thyroid autoimmune disorders in patients with chronic hepatitis $\mathrm{C}$ before and during interferon- $\alpha$ therapy. Clinical Endocrinology 199644 635-642.

10 Roti E, Minelli R, Giuberti T, Marchelli S, Schianchi C, Gardini E, Salvi M, Fiaccadori F, Ugolotti G, Neri TM \& Braverman LE. Multiple changes in thyroid function in patients with chronic active HCV hepatitis treated with recombinant interferon-alpha. American Journal of Medicine $1996 \mathbf{1 0 1}$ 482-487.

11 Zlotnik A \& Yoshle O. Chemokines: a new classification system and their role in immunity. Immunity 200012 121-127.

12 Arenberg DA, Polverini PJ, Kunkel SL, Shanafelt A, Hesselgesser J, Horuk R \& Strieter RM. The role of CXC chemokines in the regulation of angiogenesis in non-small cell lung cancer. Journal of Leukocyte Biology 199762 554-562.

13 Muller A, Homey B, Soto H, Ge N, Catron D, Buchanan ME, McClanahan T, Murphy E, Yuan W, Wagner SN, Barrera JL, Mohar A, Verastegui E \& Zlotnik A. Involvement of chemokine receptors in breast cancer metastasis. Nature 2001410 50-56.

14 Rotondi M, Lazzeri E, Romagnani P \& Serio M. Role for interferongamma inducible chemokines in endocrine autoimmunity: an expanding field. Journal of Endocrinological Investigation 20032 $177-180$.

15 Garcià-Lòpez MA, Sancho D, Sànchez-Madrid F \& Marazuela M. Thyrocytes from autoimmune thyroid disorders produce the chemokines IP-10 and Mig and attract CXCR $3^{+}$lymphocytes. Journal of Clinical Endocrinology and Metabolism 2001 86 5008-5016.

16 Romagnani P, Rotondi M, Lazzeri E, Lasagni L, Francalanci M, Buonamano A, Milani S, Vitti P, Chiovato L, Tonacchera M, Bellastella A \& Serio M. Expression of IP-10/CXCL10 and Mig/CXCL9 in the thyroid and increased serum levels of IP10/CXCL10 in the serum of subjects with recent onset Graves' disease. American Journal of Pathology 2002161 195-206.

17 Antonelli A, Rotondi M, Fallahi P, Romagnani P, Ferrari SM, Buonamano A, Ferrannini E \& Serio M. High levels of circulating CXCL10 are associated with chronic autoimmune thyroiditis and hypothyroidism. Journal of Clinical Endocrinology and Metabolism $2004895496-5499$.

18 Narumi S, Tominaga Y, Tamaru M, Shimai S, Okamura H, Nishioji K, Itoh Y \& Okanoue T. Expression of IFN-inducible protein-10 in chronic hepatitis. Journal of Immunology 1997158 5536-5544.

19 Simpson KJ, Henderson NC, Bone-Larson CL, Lukacs NW, Hogaboam CM \& Kunkel SL. Chemokines in the pathogenesis of liver disease: so many players with poorly defined roles. Clinical Science 2003104 47-63.

20 Itoh Y, Morita A, Nishioji K, Narumi S, Toyama T, Daimon Y, Nakamura H, Kirishima T \& Okanoue T. Clinical significance of elevated serum interferon- inducible protein-10 levels in hepatitis C virus carriers with persistently normal serum transaminase levels. Journal of Viral Hepatitis 20018 341-348. 
21 Butera D, Marukian S, Iwamaye AE, Hembrador E, Chambers T, Di Bisceglie AM, Charles ED, Talal AH, Jacobson IM, Rice CM \& Dustin LB. Plasma chemokine levels correlate with the outcome of antiviral therapy in patients with hepatitis C. Blood 2005106 1175-1182.

22 Carella C, Mazziotti G, Amato G, Braverman LE \& Roti E. Clinical review 169: interferon-alpha-related thyroid disease: pathophysiological, epidemiological, and clinical aspects. Journal of Clinical Endocrinology and Metabolism 200489 3656-3661.

23 Carella C, Mazziotti G, Morisco F, Manganella G, Rotondi M, Tuccillo C, Sorvillo F, Caporaso N \& Amato G. Long-term outcome of interferon- $\alpha$-induced thyroid autoimmunity and prognostic influence of thyroid autoantibody pattern at the end of treatment. Journal of Clinical Endocrinology and Metabolism 200186 1925-1929.

24 Oppenheim1 Y, Ban Y \& Tomer Y. Interferon induced autoimmune thyroid disease (AITD): a model for human autoimmunity. Autoimmunity Review 20043 388-393.

25 Shields PL, Morland CM, Salmon M, Qin S, Hubscher SG \& Adams DH. Chemokine and chemokine receptor interactions provide a mechanism for selective $\mathrm{T}$ cell recruitment to specific liver compartments within hepatitis C-infected liver. Journal of Immunology 1999163 6236-6243.

26 Burman P, Totterman TH, Oberg K \& Karlsson FA. Thyroid autoimmunity in patients on long term therapy with leukocytederived interferon. Journal of Clinical Endocrinology and Metabolism 198663 1086-1090.

27 Gogas H, Ioannovich J, Dafni U, Stavropoulou-Giokas C, Frangia K, Tsoutsos D, Panagiotou P, Polyzos A, Papadopoulos O, Stratigos A,
Markopoulos C, Bafaloukos D, Pectasides D, Fountzilas G \& Kirkwood JM. Prognostic significance of autoimmunity during treatment of melanoma with interferon. New England Journal of Medicine 2006354 709-718.

28 Rotondi M, Oliviero A, Profice P, Mone CM, Biondi B, Del Buono A, Mazziotti G, Sinisi AM, Bellastella A \& Carella C. Occurrence of thyroid autoimmunity and dysfunction throughout a nine-month follow-up in patients undergoing interferon-beta therapy for multiple sclerosis. Journal of Endocrinological Investigation 1998 11 748-752.

29 Franciotta D, Martino G, Zardini E, Furlan R, Bergamaschi R, Andreoni L \& Cosi V. Serum and CSF levels of MCP-1 and IP-10 in multiple sclerosis patients with acute and stable disease and undergoing immunomodulatory therapies. Journal of Neuroimmunology 2001115 192-198.

30 Mazziotti G, Sorvillo F, Piscopo M, Morisco F, Cioffi M, Stornaiuolo G, Gaeta GB, Molinari AM, Lazarus JH, Amato G \& Carella C. Innate and acquired immune system in patients developing interferon-alpha-related autoimmune thyroiditis: a prospective study. Journal of Clinical Endocrinology and Metabolism $2005904138-4144$.

Received 12 December 2006

Accepted 29 January 2007 